\title{
A PRODUÇÃO DO ESPAÇO E A DINÂMICA EVOLUTIVA DA HOTELARIA CURITIBANA: ESTUDO EM ‘GUIAS QUATRO RODAS’ DE 1966 A 2014
}

\author{
PRODUCTION OF SPACE AND THE EVOLUTIONARY DYNAMICS OF THE HOSPITALITY INDUSTRY \\ OF CURITIBA: A STUDY IN 'GUIAS QUATRO RODAS' FROM 1966 TO 2014
}

\section{LA PRODUCCIÓN DEL ESPACIO URBANO Y LA DINÁMICA EVOLUTIVA DE LA HOTELERÍA CURITIBANA: ESTUDIO EN 'GUIAS QUATRO RODAS' DE 1966 A 2014}

\author{
Alan Guizi \\ Professor do curso de bacharelado em Turismo, Escola de Ciências Humanas e \\ Sociais da Universidade Anhembi Morumbi \\ Mestre em Hospitalidade pela Universidade Anhembi Morumbi \\ alanguizi@gmail.com
}

\section{José Manoel Gândara}

Professor e Pesquisador do Bacharelado em Turismo, do Mestrado em Turismo e do Mestrado e Doutorado em Geografia da Universidade Federal do Paraná Doutor em Turismo e desenvolvimento sustentável pela Universidad de las Palmas de Gran Canária (Espanha) jmggandara@yahoo.com.br

Data de Submissão: 10/12/2016 Data de Aprovação: 12/07/2017

RESUMO: A localização é considerada um dos fatores para instalação de empresas ligadas à atividade turística, visto que exerce influências competitivas, como aspectos de acessibilidade, facilidades, promoção turística da cidade, entre outros fatores interligados à atividade turística. Portanto, propõe-se como problemática de pesquisa a questão, "existem relações entre contextos e eventos históricos vivenciados pela cidade de Curitiba e a dinâmica evolutiva de sua hotelaria entre 1966 e 2014?". Estabelece-se como objetivo geral: "identificar se existem relações entre contextos e eventos históricos vivenciados pela cidade de Curitiba, com a dinâmica evolutiva de seu setor hoteleiro no período de 1966 a 2014". Para tanto, esta pesquisa quantitativa de caraterística analítica adotou como método as pesquisas de palavraschave escolhidas em artigos, teses, livros e documentos on-line para a formulação das seções teóricas de estudo, que embasaram a análise dos dados da hotelaria curitibana obtidos por meio de Castro Ramos (2010) e atualizadas por meio do Guia Quatro Rodas Brasil 2014, cuja análise buscou compreender a dinâmica evolutiva da hotelaria da cidade de Curitiba, com especial atenção a 3 acontecimentos históricos transcorridos na cidade e suas possíveis influências aos hotéis. Ao final, observou-se que os números da hotelaria local apresentaram sinais de influências em face dos acontecimentos históricos, resultando-se na distribuição espacial de hotéis por Curitiba, a chegada de redes hoteleiras a Curitiba, a geração de conhecimento e inovação ante estratégias adotadas por stakeholders em busca de melhores resultados nos contextos estudados, observando-se o fenômeno de Path Plasticity.

PALAVRAS-CHAVE: Produção do espaço; Geografia econômica evolutiva; Inovação; Hotelaria; Curitiba.

ABSTRACT: Location is considered one of the factors for the installation of companies linked to tourism, generating competitive influences such as aspects of accessibility, facilities, tourist promotion of the city, and other factors. The following question was proposed as a research problem: "Is there any relationship between contexts and historical events in Curitiba and the evolutionary dynamics of its hotel industry between 1966 and 2014?". The main objective of this work, therefore, was to identify whether such relationships exist. A quantitative/analytical study was conducted, using keywords selected from articles, theses, books and online documents for the formulation of the theoretical sections of study. The study analyzed data on hotels in the city, obtained through Castro Ramos (2010) and updated through the Guia Quatro Rodas Brasil 2014, published by Abril. The aim of this analysis was to understand the evolutionary dynamics of the hotel industry in the city of Curitiba, focusing specifically on three historical events that have occurred in the city, 
ISSN: 1983-7151

and their possible influences on its hotels. In conclusion, it was found that the local hotels showed signs of influence from these historical events, resulting in the spatial distribution of hotels in Curitiba, the arrival of new hotel chains, generation of knowledge, and innovation, as a result of strategies adopted by stakeholders seeking better results in the contexts studied, and observing the phenomenon of Path Plasticity.

KEYWORDS: Production of Space; Evolutionary Economic Geography; Innovation; Hospitality.

RESUMEN: La ubicación es considerada uno de los factores para la instalación de empresas relacionadas al turismo, dado que ejerce influencias competitivas tales como aspectos de accesibilidad, instalaciones, promoción turística urbana, entre otros factores turísticos. Por lo tanto, se propone como problema de investigación la siguiente pregunta: "¿Existen relaciones entre contextos y acontecimientos históricos experimentados por Curitiba y la dinámica evolutiva de sus hoteles entre 1966 y 2014?" Se estableció como objetivo general, "identificar si existen vínculos entre contextos históricos y eventos experimentados por Curitiba, con la dinámica evolutiva de su sector hotelero en el período 19662014." Para ello, este análisis cuantitativo de característica analítica ha adoptado como método la investigación por las palabras clave elegidas en artículos, tesis, libros y documentos on line para la formulación de las secciones teóricas de estudio que apoyaron el análisis de los datos obtenidos en hoteles curitibanos por Castro Ramos (2010) y actualizados para 2014 por intermedio del Guia Quatro Rodas Brasil 2014, cuyo análisis tuvo como objetivo comprender la dinámica evolutiva de la hotelería en Curitiba, con especial atención a tres acontecimientos históricos ocurridos en la ciudad y sus posibles influencias sobre los hoteles. Al final, se observó que las cifras locales de hotelería mostraron signos de influencias frente a los acontecimientos históricos, vistos en la distribución espacial de los hoteles, la llegada de cadenas hoteleras a la ciudad, la generación de conocimiento y la innovación, frente a las estrategias adoptadas por stakeholders para la búsqueda de mejores resultados en los contextos estudiados, observando el fenómeno de Path Plasticity.

PALABRAS CLAVE: Producción del espacio; Geografía económica evolutiva; Innovación; Hotelería; Curitiba.

INTRODUÇÃO

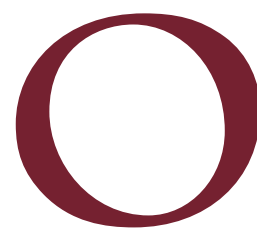

cientista Charles Darwin, ao realizar seus estudos sobre a evolução das espécies, observou que o espaço onde estes seres vivem, de certa maneira, seleciona, dentre os mais fortes, as espécies aptas para sobreviverem naquele ambiente mediante sua capacidade de adaptação, bem como sua capacidade de autodefesa de outros animais. Isso leva à evolução, dado que a reprodução e a continuidade destes seres levariam para seus descendentes o conhecimento adquirido, bem como a capacidade adquirida para sobrevivência em determinado lugar.

A história e as suas influências sobre o mundo econômico mostram que a teoria de Darwin não se restringe apenas à sobrevivência das espécies, mas também à sobrevivência e à continuidade das empresas no espaço onde ela está instalada, assim como sua continuidade no mercado, marcada por processos competitivos em que aqueles que apresentarem diferenciais valorizados por seus clientes serão aqueles naturalmente selecionados para permanecerem ativos. Considerando este contexto, propõe-se a seguinte problemática: Existem 
relações entre a evolução socioeconômica da cidade de Curitiba e a dinâmica evolutiva da hotelaria curitibana no período de 1966 a 2014 ?

Dessa forma, este estudo possui como objetivo geral "identificar se existem relações entre a evolução socioeconômica da cidade de Curitiba e a dinâmica evolutiva da hotelaria curitibana, no período de 1966 a 2014".

Estudos de dinâmica hoteleira ante contextos sociais permitem compreender efeitos diretos e indiretos em um dos principais stakeholders da atividade turística, cuja compreensão auxilia em processos de tomadas de decisões, criando-se condições baseadas no histórico do espaço estudado para ações futuras.

Teorias com base em dependência de trajetória (ou do inglês, path dependence) são compreendidas com base na geografia econômica evolutiva, um dos conceitos utilizados neste estudo, o qual dá conta de entender a dinâmica do espaço baseada em sua produção social, econômica e cultural, selecionando-se a cidade de Curitiba (capital do estado do Paraná) como objeto de estudo, haja vista sua reputação em mídia como cidade modelo, cidade sustentável e cidade inovadora, posicionando-a como fundamental para o turismo brasileiro.

Em um estudo em que se busca compreender o processo de evolução hoteleira, a escolha por Curitiba se deu de modo a compreender se sua retórica inovadora também é refletida em seu setor empresarial turístico com foco na hotelaria. Mas se destaca também o fato da existência de estudos anteriores abordando esta temática oriundas da Universidade Federal do Paraná, os quais foram amplamente utilizados no presente artigo, sendo descritos na seção 'método' a seguir.

\section{MÉTODO}

Este estudo foi desenvolvido em duas etapas, sendo a primeira etapa baseada na pesquisa em artigos, teses, livros, documentos on-line, textos jornalísticos e outros, de referências bibliográficas acerca das palavras-chave escolhidas, estabelecendo-se as seções temáticas "Produção do espaço e o turismo" e "Geografia econômica evolutiva". 
A segunda etapa, por sua vez, utilizou como base as pesquisas realizadas e publicadas por meio da tese de doutorado de Castro Ramos (2010), realizada no programa stricto sensu em Geografia da Universidade Federal do Paraná (UFPR), em que considerou informações disponíveis acerca da hotelaria curitibana nos Guias Quatro Rodas da Editora Abril dos anos de 1966, 1972, 1978, 1984, 1990, 1996, 2002 e 2008, ficando a cargo deste estudo a atualização dos dados conforme o Guia Quatro Rodas do ano de 2014.

Contudo, vale destacar que durante os estudos que geraram os guias anuais, por motivos editoriais, os Guias Quatro Rodas não consideraram os hotéis curitibanos em sua totalidade. Conforme o editor, Peixoto (2013), essa opção se deu:

Elegemos os melhores para o leitor (...). Isso pode dever-se a diversos fatores, como relação custo-benefício ruim, má conservação e serviço inadequado - o que identificamos quando nos hospedamos anonimamente. Há donos de hospedagens que discordam dos métodos de classificação e pedem para ter seus estabelecimentos excluídos de nossas publicações - e são atendidos caso insistam na ideia mesmo após contato do editor responsável.

Dessa forma, analisa-se neste estudo, por meio dos dados obtidos, a evolução histórica e econômica do município de Curitiba, com foco na capacidade de geração de conhecimentos em gestão por stakeholders hoteleiros, que buscam aproveitar momentos históricos para inovar e obter melhores resultados face as possibilidades existentes, bem como observações acerca do uso de tecnologias.

Transversalmente, considerou-se ao longo deste estudo três momentos, ou eventos, em especial acontecidos na cidade de Curitiba, responsáveis por alterações no espaço do município, evoluções na distribuição espacial de empresas curitibanas, assim como responsáveis por trazer visibilidade à cidade, carecendo novos investimentos e políticas públicas em infraestrutura e promoção, sendo eles: (1) A criação da Cidade Industrial de Curitiba, em 1972; (2) A instalação de montadoras automobilísticas e a transferência de empresas multinacionais para Curitiba e região metropolitana, na segunda metade da década de 1990; (3) A Copa do Mundo de Futebol da FIFA em 2014, tendo Curitiba como uma das sedes de jogos. 
Os dados coletados foram organizados em forma de quadros e figura, divididos e atualizados conforme apresentados em Castro Ramos (2010), de modo a possibilitar a análise da dinâmica evolutiva hoteleira ao longo do tempo, assim como cruzar tais informações com o marco teórico de Geografia Econômica Evolutiva, com especial atenção à dependência da trajetória (do inglês, path dependence), validando-se a teoria ante a realidade observada, método nomeado por Laville e Dionne (1999) como emparelhamento, formando-se ao final a seção de estudo "Análise da dinâmica evolutiva curitibana de 1966 a 2014".

No entanto, observou-se que alguns dados presentes nos quadros e nas figuras de Castro Ramos (2010) não foram contemplados ou atualizados no Guia Quatro Rodas Brasil de 2014, sendo acrescentados nestes casos a sigla "s/i" que, para efeitos deste estudo, significa "sem informações".

Ao final, apresentam-se as considerações finais, e nesta, a resposta à problemática proposta por meio do atingimento ao objetivo geral de pesquisa, além de sugestões para próximas pesquisas por intermédio das considerações finais.

\section{A PRODUÇÃO DO ESPAÇO E O TURISMO}

Conforme Santos (1982), o espaço não é um fim em si, já que não é independente das relações sociais e econômicas que transcorrem sobre o mesmo. O autor cita quatro categorias que devem ser consideradas para análise do espaço geográfico de modo que seja compreendida a totalidade social espacializada, sendo eles (Santos, 1982):

- Forma: Aspecto visíveis, exterior de um objeto;

- Função: Atividade ou papel de um objeto criado;

- Estrutura: Modo como os objetos estão organizados, inter-relação entre si;

- Processo: Ação contínua, implicando em mudanças ante o tempo;

Com isso, a produção do espaço ocorre por meio das relações sociais e econômicas transcorridas sobre o mesmo, resultado da apropriação do espaço como processo da reprodução ininterrupta da vida (Carlos, 2016) 
Lefebvre (1981 como citado em Schmid, 2012) destaca que a produção do espaço é resultado de uma série de instituições e relações ocorridas ao longo do tempo, tais como o comando do Estado, o saber e o conhecimento, as relações sociais e instituições gerais da sociedade, sendo ressaltado:

[...] o modo de produção organiza, produz, ao mesmo tempo que certas relações sociais, seu espaço (seu tempo). É assim que ele se realiza, posto que o modo de produção projeta sobre o terreno estas relações, sem, todavia deixar de considerar o que reage sobre ele. (Lefebvre, 1981, p. vii como citado em Carlos, 2016, p.57).

A noção da produção do espaço também repousa na ideia, conforme Limonad (1999, p.81), de estratégias ligadas à reprodução do capital e do trabalho, bem como das práticas sociais que visam tanto manter o espaço social com está, quanto mudá-lo de forma abrupta e radical.

Paiva (2008) indica que o espaço é também um produto consumível, ao passo que atividades como a turística se apropriam do mesmo, provocando transformações no espaço tanto no destino receptor quanto no emissor, sem desconsiderar o espaço de deslocamento do turista. Com isso, conforme o autor, o turismo se desenvolve pelo uso indiscriminado pelo espaço, subtraindo-se a dicotomia da paisagem urbana e rural, avançando sobre diversas frentes, como em turismo rural, turismo urbano, turismo de "sol e mar", entre outros.

O espaço urbano tem sido alvo de intervenções, ao passo que determinadas atividades desenvolvem-se no mesmo, tal como o consumo do espaço para o lazer e o turismo, por meio da construção de cenários culturais, aproveitando-se de sua qualidade paisagística, a fim de impulsionar o comércio e a prestação de serviços. A justificativa utilizada para a intervenção turística no espaço repousa na reconstrução da imagem de antigos centros urbanos, para a capitalização e composição de novas centralidades (França, 2016).

Hayllar et al. (2011, p.4) definem estes espaços onde transcorrem as atividades interligadas ao turismo como "áreas funcionais turísticas", especialmente àqueles localizados em áreas urbanas que, segundo os autores, tratam-se de regiões geograficamente pequenas e bem definidas, com concentrações de serviços relacionados ao turismo, com identidade espacial, cultural, social e econômica em distinta. 
Neste sentido, Coriolano (2009) explica áreas de concentrações de empresas inter-relacionadas em regiões geograficamente definidas como clusters, sistema produtivo local, arranjo produtivo local, dentre outras classificações, diferenciando-se apenas em tamanho e estágio de desenvolvimento e cooperação, baseando-se nos estudos de Porter (1999), nos quais é abordado o conceito de aglomerado como o agrupamento geograficamente concentrado de empresas interconectadas e inter-relacionadas numa determinada área, vinculadas por elementos comuns e complementares.

Dentre as empresas consideradas subsegmentos da atividade turística, a hotelaria é responsável pela atividade de hospedagem de turistas, bem como responsável pelo oferecimento de conforto e atividades diversas ao visitante durante seu período de hospedagem.

Portanto, essas empresas recebem influências da localização onde estão instaladas, de acordo com a concentração de empresas consideradas complementares à atividade turística, assim como pelo modo de consumo do espaço pelo próprio turismo, definindo-se sua segmentação de público e, por consequência, sua infraestrutura para atendimento aos seus clientes/hóspedes, tornando-se este um fator de construção e valorização da imagem turística de uma dada cidade (Pereira \& Spolon, 2007).

Nunes (2014, p.327) salienta que a produção do espaço para o turismo:

[...] passa, necessariamente, pelo aumento da fluidez do território e pela produção, consequentemente, de melhores condições de circulação. Tais atitudes não garantem apenas o deslocamento e a mobilidade do turista e do residente, mas principalmente, a mobilidade e a fluidez do capital financeiro, investidor, que se utiliza das ações do Estado, as quais valorizam determinadas regiões e, consequentemente, valorizam seus empreendimentos.

Tais influências de localizações hoteleiras são compreendidas por meio de Egan e Nield (2000) através da identificação de hierarquias de hotéis segundo seus pontos de instalações em meio a cidade onde, segundo os autores, os hotéis mais luxuosos estão localizados no centro das cidades, baixando-se a hierarquia hoteleira ao passo que se distancia desta área (Figura 1). 


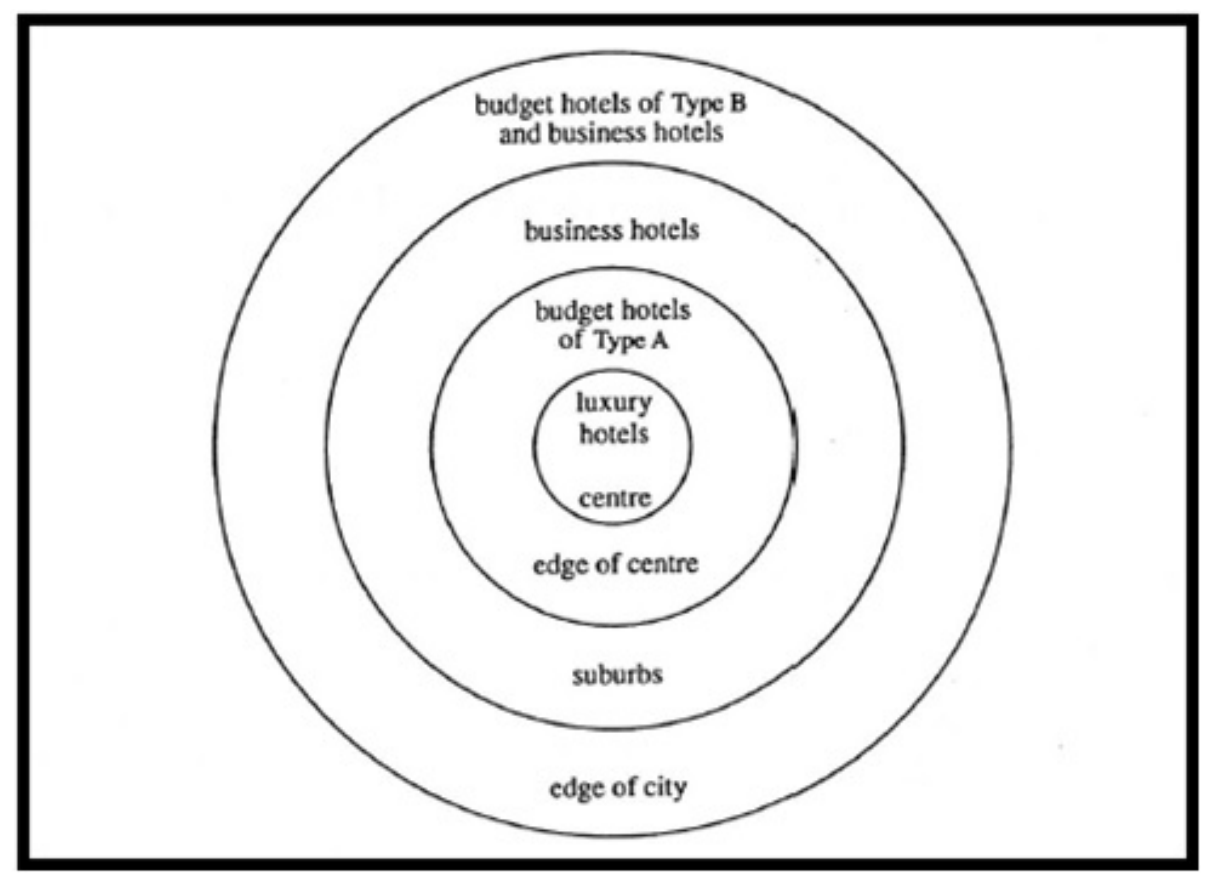

Figura 1: A hierarquia espacial dos tipos de hotéis

Fonte: Egan \& Nield, 2000, p.612.

Por meio da Figura 1, nota-se que, segundo os autores, a hierarquia hoteleira é definida por: 1 ) hotéis de luxo (4 a 5 estrelas) localizados nos centros das cidades; 2) hotéis econômicos do tipo ' $A$ ' (indicando-se hotéis de 4 estrelas) localizados nas bordas dos centros urbanos; 3 ) hotéis de negócios (no geral de 3 estrelas) localizados fora do centro da cidade, no entanto em áreas próximas, indicando-se, portanto, distritos de negócios e; 4) hotéis econômicos do tipo 'B' ou de negócios, localizados nas saídas das cidades (Egan \& Nield, 2000; Castro Ramos, 2010)

Do ponto de vista empresarial, a definição de hierarquias para instalações de empresas hoteleiras é identificada por meio de 4 itens, sendo eles: i) acessibilidade ao centro da cidade, dado que este é um pouco visto como o "mais acessível da cidade" sob a ótica dos meios de transportes, trabalho e mercado; ii) acessibilidade especial, usualmente ligado à concentração ou à aglomeração de economias e empresas complementares, ou de espaços relevantes para o viajante de lazer ou negócios; iii) outros fatores como a influência histórica, topográfica, do tamanho da cidade, bem como influências mercadológicas e do capital que, como já descrito, oferece ao visitante uma série de facilidades de mobilidade, restauração, lazer e entretenimento e outros; iv) questões dinâmicas, ligadas às mudanças nas escolhas por viagens, estilo de vida, busca por lazer, entre outros, concentrandose no centro a maior parte dos espaços ligados às diversas tribos e preferências (Harvard, 1996 como citado em Egan \& Nield, 2000, p.614). 
A localização hoteleira influencia diretamente a escolha de turistas, dado que, como descrito anteriormente, permite que o mesmo esteja próximo dos locais mais relevantes à visitação turística. Shoval et al. (2011) destacam que os locais da cidade com mais atratividade turística são aqueles que apresentam ancoragens ligadas às aglomerações comerciais, atrações turísticas, espaços para compras e entretenimento, distritos ou áreas centrais de negócios e presença de outros meios de hospedagem.

Outro fator de destaque com relação à 'localização' está na proximidade de meios de hospedagens aos centros de convenções, haja vista que a proximidade destes espaços gera potencial de hospedagem aos hotéis das intermediações, já que serão os primeiros a receber influências dos eventos que transcorrem. Outros locais de influências aos hotéis urbanos são considerados os pontos de acesso à cidade, tais como a rodoviária e o transporte para o aeroporto, aspectos que atendem às necessidades tanto do turismo de lazer quanto de negócios e eventos (Hocayen-da-Silva \& Teixeira, 2007, p.29).

Asworth e Haan (1985), citados em Pearce (2003, p.314), detalham a distribuição hoteleira em contexto geral, porém se observando sua especialidade para cidades histórico-turísticas, a qual, mesmo assim, vale o destaque, caracterizando-se e apontando-se ao centro do mapa o centro histórico da cidade e seu distrito central de negócios (do inglês, Central Business District - CBD).

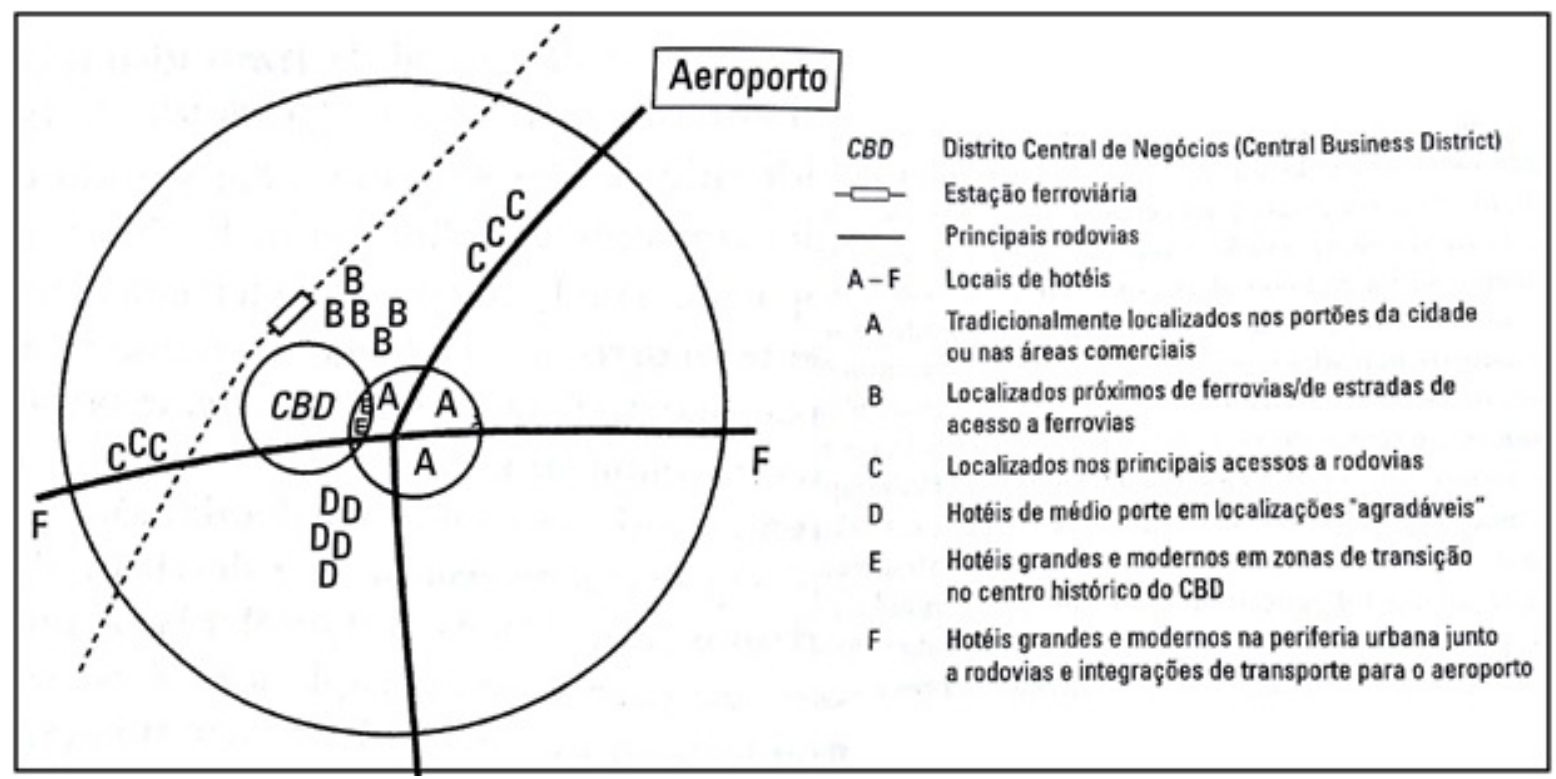

Figura 2: Tipologia das localizações de hotéis urbanos

Fonte: Asworth \& Haan (1985 como citado em Pearce, 2003, p.314) 
Segundo os autores, os hotéis estão localizados em pontos de acessibilidade à cidade, como ferrovias, aeroportos e rodovias (orientados pela "localização", representados por hotéis $\mathrm{B}, \mathrm{C}$ e F), e próximos de áreas centrais, como o centro histórico e os distritos de negócios (orientados para o "mercado", representados por hotéis A, D e E) (Asworth \& Haas, 1985, como citado em Pearce, 2003).

Um hotel do centro da cidade responde às necessidades de toda uma variedade de visitantes urbanos, cuja estada costuma ser relativamente breve, em geral de dois a quatro dias. Muitos viajantes de negócios valorizam a proximidade do CBD para que possam fazer seus negócios de maneira célebre e eficiente. Também ali o visitante orientado para as compras pode se deparar com uma profusão de lojas sofisticadas. É também no centro que o turista em visita a atrações encontrará muitos dos edifícios e monumentos históricos, e outras opções culturais da cidade. (Pearce, 2003, p.306-307).

Para tanto, busca-se compreender, nas seções a seguir, as influências do espaço para a evolução da gestão e da inovação tanto no turismo quanto, especialmente, de empresas hoteleiras a qual foi aplicada à realidade curitibana (Paraná), por meio de análises da produção econômica do espaço curitibano, influências da dinâmica evolutiva do espaço aos seus agentes econômicos interligados ao turismo, sob o prisma da teoria da geografia econômica evolutiva, levando-os à tomada de decisão com base na trajetória e nos contextos históricos urbanos, dentre outros aspectos.

\section{GEOGRAFIA ECONÔMICA EVOLUTIVA}

A geografia econômica possui como objeto de estudo a superfície da terra com vistas aos seus aspectos econômicos, tomando-se como partida a análise das relações espaciais baseadas no mundo econômico e na capacidade do espaço em produção e reprodução do capital (Chorincas, 2001).

Por meio da geografia econômica buscam-se teorias, modelos formais e métodos de análise econômicos para compreensão de fenômenos econômicos sobre o espaço, buscando-se compreender o desenvolvimento econômico de regiões, na organização espacial da economia, da distribuição e do consumo ao longo do tempo e, ainda, como as estruturas espaciais produzem feedback 
para influenciar as forças motrizes da evolução da economia (Domareski Ruiz, Miki \& Gândara, 2014; Boschma \& Martin, 2010).

Dessa forma, o enfoque principal de geografia econômica está na compreensão das alterações sob o espaço decorrentes de influências econômicas, assim como as influências geradas pelo capitalismo observadas em empresas, produtos, novas tecnologias, indústrias, postos de trabalho, assim como o desaparecimento dos mesmos decorrentes de contextos territoriais e econômicos (Boschma \& Martin, 2010).

Dentre as teorias da geografia econômica, as teorias evolutivas vindas da economia evolucionária surgiram a partir de 2003, tratando-se da produção constante do conhecimento e das influências das mudanças econômicas ante contextos e processos históricos sofridos por regiões (Domareski Ruiz, 2015).

Frenken (2007) mostra que a geografia econômica evolutiva é o ramo da geografia que aborda a economia como um processo evolutivo que se desenrola no espaço e no tempo. Portanto, busca-se por meio da geografia econômica evolutiva compreender as interdependências desenvolvidas entre stakeholders de processos econômicos transcorridos em determinadas regiões, subdividindo-se em três pilares, conforme Figura 3:

\begin{tabular}{|c|c|c|c|}
\hline \multicolumn{4}{|c|}{ GEOGRAFIA ECONÔMICA EVOLUTIVA } \\
\hline \multicolumn{2}{|c|}{ Path Dependence } & $\begin{array}{c}\text { Complexity } \\
\text { Theory }\end{array}$ & $\begin{array}{l}\text { Generalised } \\
\text { Darwinism }\end{array}$ \\
\hline \multicolumn{2}{|c|}{$\begin{array}{c}\text { Contexto } \\
\text { Contingência } \\
\text { Fatos Históricos } \\
\text { Institucionalização } \\
\text { Momento Critico } \\
\text { Estratégia de Decisão }\end{array}$} & \multirow{4}{*}{$\begin{array}{c}\text { Surgimento } \\
\text { Auto-organização } \\
\text { Adaptação }\end{array}$} & \multirow{4}{*}{$\begin{array}{l}\text { Novidade } \\
\text { Variedade } \\
\text { Seleção } \\
\text { Continuidade }\end{array}$} \\
\hline Path Creation & Path Plasticity & & \\
\hline $\begin{array}{c}\text { Stakeholders } \\
\text { Relaçōes Humanase } \\
\text { Sociais }\end{array}$ & $\begin{array}{l}\text { Tecnologia } \\
\text { Evolução do } \\
\text { Conhecimento }\end{array}$ & & \\
\hline Inovação & $\begin{array}{l}\text { Mudanças Incrementais } \\
\text { Continuidade } \\
\text { Inovação }\end{array}$ & & \\
\hline
\end{tabular}

Figura 3: Pilares da Geografia Econômica Evolutiva

Fonte: Adaptado de Domareski Ruiz, 2015.

Um dos pilares da geografia econômica evolutiva, a teoria da complexidade, foi estudada pela primeira em vez sob a luz da termodinâmica e, posteriormente, 
ISSN: 1983-7151

aplicada à economia. Entende-se que o cenário econômico apresenta características comuns com sistemas adaptativos complexos e, dessa forma, sua evolução pode ser explicada por processos de surgimento, auto-organização e adaptação (Domareski Ruiz, 2015).

Munné (1995, como citado em Torres, 2005) mostra que a realidade "é nãolinear", e dessa forma caótica e difusa, se caracterizando por sistemas cujas implicações de seus integrantes não seguem uma ordem pré-estabelecida e dessa forma, pequenas alterações não produzem necessariamente pequenos efeitos, mas podem causar grandes diferenças, utilizando-se assim o termo "evolutivo", dado que não existe modo de reverter tais mudanças (Byrne, 1998).

Dessa forma, é possível compreender por meio da teoria da complexidade que a dependência da trajetória (path dependence) coevolui por meio de diferentes indústrias locais, assim como empresas de diferentes tecnologias e atividades em que cada uma possui uma forma diferente e visões diferentes de evolução dentro de suas possibilidades, resultando em uma economia de sistemas abertos sujeita a interações dinâmicas constantes de stakeholders. Isto implica afirmar que as evoluções dessas organizações podem não corresponder necessariamente à trajetória institucional da própria região, mas permite que o desenvolvimento de novas tecnologias e indústrias coexistam com os caminhos já existentes (Brouder \& Eriksson, 2013).

O darwinismo generalizado (do inglês, generalised darwinism), por sua vez, é considerada a teoria mais abordada pela geografia econômica evolutiva e utiliza-se da teoria evolutiva de Darwin de seleção natural, em que os mais bem adaptados ao meio terão mais chances de sobrevivência, sendo estes selecionados para aquele ambiente, ao contrário daqueles menos adaptados (Domareski Ruiz, 2015).

Portanto, o darwinismo aplicado à economia resulta nos estudos acerca da concorrência entre agentes em uma dada região ou ambiente, tendo em conta sua capacidade de inovação e apresentação de novidades, variedades, seleção e continuidade (Brouder \& Eriksson, 2013).

Aldrich et al. (2008) reforçam que, sem o princípio da seleção, não há nenhuma explicação de como uma entidade prevalece sobre outras. Os autores ressaltam 
que o darwinismo leva às comparações entre concorrentes, resultando em ações de competitividade que visam à criação de novos produtos ou indústrias em diferentes contextos geográficos ou industriais, considerando-se a criação de um novo ambiente e o relativo isolamento de um grupo dos demais concorrentes, criando-se novas oportunidades por meio da variação.

Por fim, a dependência da trajetória (do inglês, path dependence) surgiu na economia da tecnologia e se desenvolve em virtude da realização de observações comparadas em ciência política por meio de trajetórias históricas (Fernandes, 2002), auxiliando na compreensão e na tomada de decisões políticas em uma dada região ou país, em concordância com Kato (1996 como citado em Fernandes, 2002), ao afirmar que "eventos passados influenciam a situação presente" (Kato, 1996, p.1, como citado em Fernandes, 2002, p.79)

Com isso, busca-se por meio da dependência da trajetória fornecer indicativos da importância do contexto ou de eventos históricos no decorrer de um dado processo econômico, bem como suas influências aos stakeholders pertencentes a uma dada região capaz de sofrer influências ou influenciar a mesma, sendo instituições públicas ou privadas, dentre outros atores (Bernardi, 2012).

A teoria de path dependence é considerada conceito central em abordagens evolutivas, dado que ajuda a explicar como o conjunto de decisões estratégicas está ligada às decisões igualmente importantes tomadas no passado que, por sua vez, divide-se em path creation e path plasticity (Domareski Ruiz, 2015).

Path creation, nas palavras de Garud e Karnoe (2001), é considerada contrastante ao modelo de path dependence, apesar de ambas utilizarem-se de fenômenos ou eventos capazes de refletir e/ou moldar ações futuras. Contudo a maior diferença entre ambas, é que em path dependence, seus stakeholders são considerados observadores passivos de eventos da história, enquanto em path creation esses mesmos stakeholders agem durante seu acontecimento (ou em tempo real, conforme os autores) de modo a criar novos caminhos, visando a novos campos de exploração que interrompem o seguimento normal de um processo por meio de uma nova estratégia. Contudo, erros acontecem e, por meio deles tais ações ou eventos tornam-se necessários para que ações assertivas sejam identificadas e, por fim, avanços sejam feitos. 
Por outro lado, o conceito de path plasticity, de acordo com Strambach e Halkier (2013), também envolve mudanças dinâmicas causadas por stakeholders (forças sociais) em processos e fenômenos aleatórios, contudo em path plasticity essas ações, em comparação com path creation, caracterizam-se por manter o seguimento normal de um processo dinâmico, aplicando-se estratégias que redesenham suas regras por meio da tecnologia ou da inovação, garantindo, ao final, o sucesso desse caminho (Domareski Ruiz, 2015).

Strambach e Halkier (2013) apontam que a geografia econômica evolutiva desempenha um importante papel em path plasticity, pois os processos dinâmicos de desenvolvimento regional ampliam a natureza dos processos de inovação, assim como a importância da integração entre atores sociais, tendo em vista o desenvolvimento regional, além do desenvolvimento do conhecimento, da inovação, da tecnologia e da própria economia.

Os estudos em geografia econômica evolutiva abrem caminhos para a compreensão do turismo, bem como seus efeitos ao espaço onde esta atividade acontece, dado queenvolvematoressociais, políticas públicas, esforços promocionais e investimentos financeiros, buscando-se como resultado o desenvolvimento dinâmico da economia regional (Ioannides, Halkier \& Lew, 2015).

\section{A DINÂMICA EVOLUTIVA DA HOTELARIA CURITIBANA DE 1966 A 2014}

A cidade de Curitiba, capital do estado do Paraná, é, segundo estimativas do IBGE (2016), lar de mais de 1,8 milhão de pessoas, formada por brasileiros vindos das diversas regiões do país, bem como imigrantes especialmente vindos da Alemanha, Itália, Ucrânia, Polônia, entre outros. A cidade, que é considerada rica em cultura, gastronomia e opções de lazer em áreas verdes, oferece também oportunidades de negócios seja em atividades de eventos ou juntamente às empresas presentes na cidade (Curitiba Turismo, s/d).

Este crescimento e esta visibilidade foram adquiridos ao longo do tempo, transformando Curitiba em palco de acontecimentos que transformaram seu espaço urbano, o cotidiano de seus moradores e de seus visitantes, acentuando em infraestrutura urbana, competitividade em negócios e turismo, aumento da 
influência da cidade no cenário nacional e internacional e, sobretudo, conforme ressaltado por Pereira e Spolon (2007), auxiliando na construção da imagem turística da cidade.

Portanto, busca-se compreender, por meio de contextos históricos ocorridos sobretudo na cidade de Curitiba, as possíveis influências ao setor hoteleiro da cidade, sobretudo acerca de estratégias para permanência e sobrevivência em mercado, conforme apontado nos quadros a seguir, permitindo análise ante a períodos de acontecimentos.

Por meio do Quadro 1, considerando-se os momentos históricos em Curitiba, observa-se a duplicação no número de hotéis avaliados na cidade de Curitiba entre os anos 1966 e 1972 (período da instalação da Cidade Industrial de Curitiba) e crescimentos para 54 hotéis no ano de 1990, mantendo-se o mesmo patamar de hotéis avaliados em 1996, com pequena queda de 2 hotéis (período da instalação de montadoras de automóveis e multinacionais em Curitiba e região metropolitana).

No entanto, neste mesmo quadro, apresentam-se os números de hotéis na cidade durante o ano de 2014, período de realização da Copa do Mundo da FIFA de 2014 que, por sua vez, registrou 70 hotéis avaliados, permanecendo relativamente igual ao período anterior analisado, ano de 2008, o que está de acordo com o estudo denominado "Placar hotelaria", desenvolvido por meio da parceria entre Fórum de Operadores Hoteleiros do Brasil (FOHB) e Hotel Invest (2015), o qual mostrou que, dentre as cidades brasileiras que receberam jogos da Copa do Mundo da FIFA de 2014, a cidade de Curitiba é uma das únicas onde a hotelaria disponível foi suficiente para abrigar a demanda causada pelo evento, mantendo sua hotelaria em níveis saudáveis, com margens operacionais e rentabilidades adequadas aos investimentos realizados (Fohb \& Hotel Invest, 2015).

Trotta, Strehlau e Turolla (2015), em seu estudo acerca da imagem da cidade durante megaeventos, cujo método incluiu pesquisas em artigos jornalísticos que abordavam temas acerca da cidade sobretudo durante a Copa do Mundo da FIFA de 2014, ressaltam que Curitiba obteve maior projeção jornalística devido à sua infraestrutura e sustentabilidade. As autoras levantam a hipótese de que o fato de a entidade FIFA ter escolhido a cidade de Curitiba como 
uma das sedes dos jogos foi devido à sua infraestrutura urbana, reconhecida internacionalmente; e devido às inovações alcançadas para soluções de problemas ligados ao transporte, sustentabilidade e reciclagem, comparada constantemente com cidades internacionais, como Madrid e Singapura (Trotta, Strehlau \& Turolla, 2015, p.295).

Atender às expectativas do turista durante suas primeiras visitas é considerado essencial para fidelização dos mesmos, para isso se faz necessário não apenas a criação de produtos e serviços, mas também geri-los, compreendendo-os a fundo e desenvolvendo estratégias e ações aproveitando as potencialidades do destino para superação das expectativas de seus turistas (Oliveira \& Gândara, 2015)

No entanto, com relação à hotelaria, esta mesma realidade não foi observada em outras cidades onde os jogos ocorreram, o que foi necessária a construção de novos empreendimentos para atender à demanda gerada pelos jogos, resultando em superoferta hoteleira após a competição, dado que a demanda recebida por essas cidades não atinge o novo número de unidades habitacionais disponíveis (Fohb \& Hotel Invest, 2015).

\begin{tabular}{|c|c|c|c|c|c|c|c|c|c|}
\hline BAIRRO & 1966 & 1972 & 1978 & 1984 & 1990 & 1996 & 2002 & 2008 & 2014 \\
\hline Centro & 7 & 15 & 36 & 40 & 46 & 43 & 50 & 42 & 39 \\
\hline São Francisco & 0 & 1 & 1 & 1 & 1 & 0 & 1 & 2 & 1 \\
\hline Centro Cívico & 0 & 0 & 0 & 0 & 1 & 0 & 2 & 3 & 3 \\
\hline Alto da Glória & 0 & 0 & 0 & 0 & 1 & 0 & 0 & 0 & 0 \\
\hline Alto da Rua XV & 0 & 0 & 0 & 0 & 0 & 0 & 2 & 3 & 2 \\
\hline Rebouças & 0 & 0 & 0 & 0 & 0 & 1 & 0 & 1 & 1 \\
\hline Água Verde & 0 & 0 & 0 & 0 & 0 & 0 & 1 & 1 & 0 \\
\hline Batel & 0 & 0 & 0 & 0 & 0 & 1 & 4 & 14 & 15 \\
\hline Bigorrilho & 0 & 0 & 0 & 0 & 0 & 0 & 0 & 2 & 2 \\
\hline Prado velho & 0 & 0 & 0 & 0 & 1 & 1 & 1 & 0 & 0 \\
\hline Portão & 0 & 0 & 1 & 1 & 0 & 0 & 0 & 0 & 0 \\
\hline Campina do Siqueira & 0 & 0 & 0 & 0 & 1 & 1 & 0 & 0 & 1 \\
\hline Bairro Alto & 0 & 0 & 0 & 0 & 0 & 0 & 0 & 0 & 0 \\
\hline Santa Felicidade & 0 & 0 & 0 & 0 & 0 & 0 & 0 & 1 & 1 \\
\hline Cidade Industrial de Curitiba & 0 & 0 & 0 & 0 & 1 & 1 & 1 & 2 & 2 \\
\hline Uberaba & 0 & 0 & 0 & 0 & 0 & 0 & 0 & 0 & 1 \\
\hline Campo Comprido & 0 & 0 & 0 & 0 & 0 & 0 & 0 & 0 & 1 \\
\hline Mercês & 0 & 0 & 0 & 0 & 0 & 0 & 0 & 0 & 1 \\
\hline Total de hotéis no período & 7 & 16 & 38 & 44 & 54 & 52 & 62 & 71 & 70 \\
\hline
\end{tabular}

Quadro 1: Crescimento da hotelaria por bairros de Curitiba.

Fonte: Adaptado de Castro Ramos (2010) 
No Quadro 1 observa-se também a manutenção da região central da cidade como principal polo de hospedagem em número de hotéis ao longo do tempo, dada a facilidade de acesso à cidade por meio da região central, bem como a conformação de um polo próximo à Rodoferroviária, local de chegada e partida de ônibus que ligam a cidade às cidades tanto dentro quanto fora do Paraná. Além da proximidade ao Aeroporto Afonso Pena, no município de São José dos Pinhais, cuja avenida de ligação está próxima à região central (Avenida Comendador Franco e Avenida das Torres em sequência), importantes pontos de chegada e saída de Curitiba. Vale ressaltar que mesmo estando no município de São José dos Pinhais, a conformação do polo hoteleiro próximo ao aeroporto é outro elemento relevante.

Apesar do centro da cidade de Curitiba permanecer na liderança em número de hotéis, observa-se queda a partir de 2008, além da instalação de hotéis em outros bairros da cidade com tendências aos negócios, ainda que próximos ao centro, com destaque ao Bairro Batel, devido à sua localização intermediária entre o centro da cidade e a Cidade Industrial de Curitiba, além deste bairro também servir como um Distrito Central de Negócios, instalada no município a partir do início dos anos de 1970, corroborando com Boschma e Martin (2010), já abordado neste estudo, abrindo-se caminho para o desenvolvimento econômico de outras regiões da cidade por meio da distribuição espacial do consumo ao longo do tempo.

O fato do crescimento acentuado de hotéis em bairros localizados na região central-histórica de Curitiba, ao Batel (seu distrito central de negócios) e aos pontos de acesso à cidade corrobora com o mapa das localizações de hotéis urbanos destacados em Ashworth e Haan (1985, como citado em Pearce, 2003), haja vista que seus turistas a negócios e eventos representam mais de $50 \%$ do total de visitantes recebidos pela cidade, portanto com períodos de permanência relativamente curtos, motivo pelo qual o Curitiba Convention \& Visitors Bureau investe em programas como "Curta Curitiba por mais 2 dias" (Curitiba, região e litoral Convention \& Visitors Bureau, s/d).

A cidade de Curitiba, também ao longo do tempo, tem recebido hotéis de redes tanto paranaenses (tendo a cidade como local de fundação) quanto nacionais e internacionais, além das instalações de hotéis considerados 
independentes, dado que não estão associados a nenhuma rede, cuja evolução no período estudado é apresentada na Figura 4.

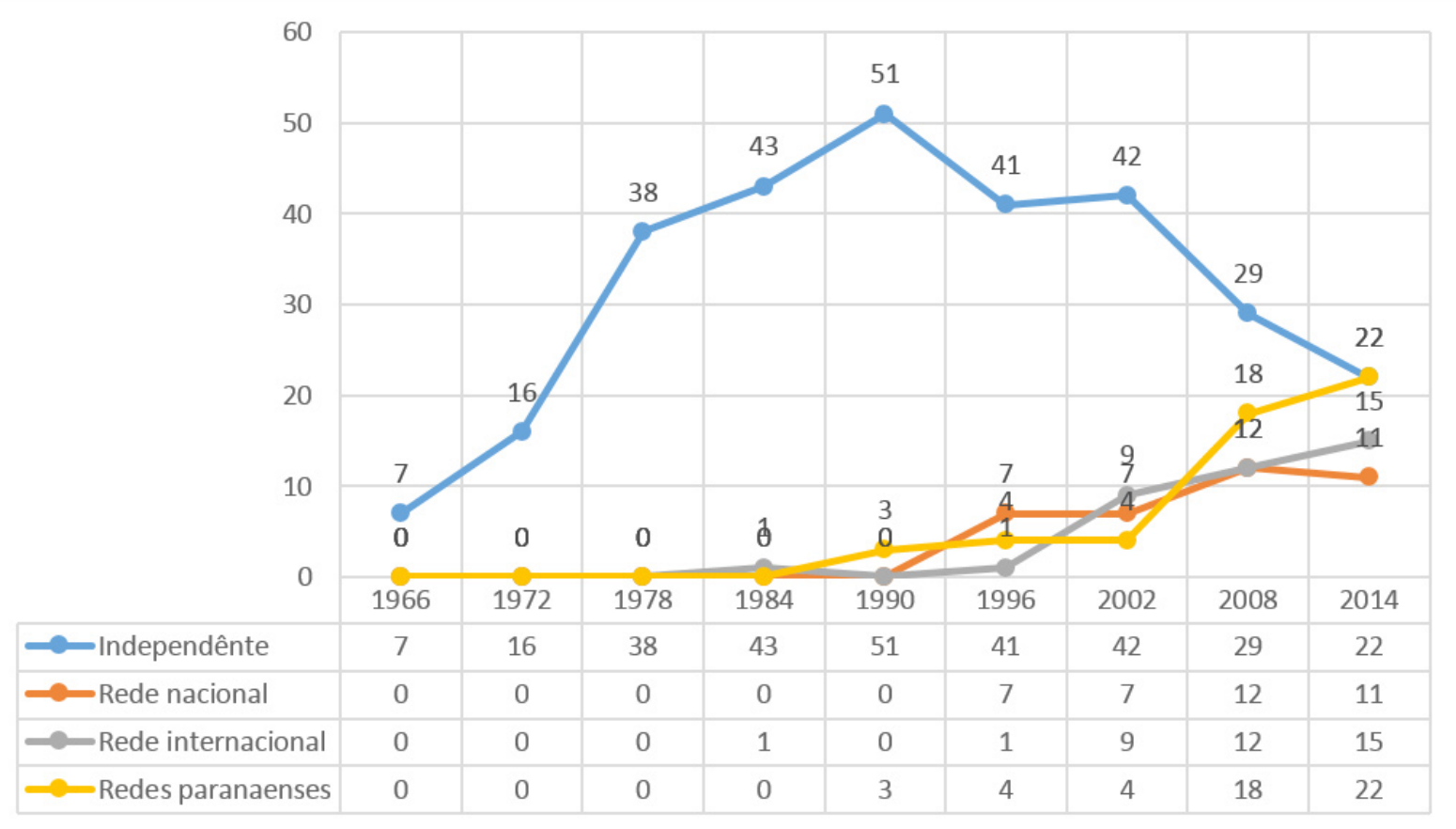

Figura 4: Organização dos hotéis

Fonte: Adaptado de Castro Ramos (2010).

Por meio da Figura 4, observa-se o salto no número de hotéis independentes no ano de 1972 (período da instalação da Cidade Industrial de Curitiba), passando para 38 hotéis em 1978, permanecendo acima do número de hotéis de redes paranaenses, nacionais e internacionais até o ano de 2014, momento em que o número de hotéis de redes paranaenses toma a dianteira no gráfico, resultado não apenas de novos hotéis de redes paranaenses sendo instalados na cidade, mas também da queda expressiva no número de hotéis independentes após o ano de 2002.

Vale ressaltar que, se somados os números de hotéis de redes paranaenses aos números apresentados por redes nacionais, o número de hotéis independentes seria ultrapassado ainda no ano de 2008, totalizando-se 30 hotéis de redes brasileiras contra 29 hotéis independentes. Em 2014, esta diferença saltaria para 33 hotéis de redes brasileiras, contra 22 hotéis independentes, levantando a hipótese da associação de hotéis outrora independentes às redes brasileiras e/ou internacionais como uma estratégia de sobrevivência e continuidade no mercado, para aproveitamento da demanda gerada pela Copa do Mundo da FIFA de 2014. 
Por meio da Figura 4, nota-se a chegada da primeira rede internacional de hotéis no ano de 1984, no entanto foi apenas a partir do ano de 1996 é que a permanência dessas redes atingiu sua solidez. Por sua vez, as redes brasileiras entraram na cidade de Curitiba (muitas delas sendo fundadas na própria cidade de Curitiba) a partir de 1990 e, apresentaram crescimento nos anos sequenciais, alcançando participação majoritária em Curitiba a partir de 2008 e consolidando-se em 2014.

Outro aspecto analisado na hotelaria curitibana é sua evolução na oferta de áreas diversas para seus hóspedes, complementando sua experiência de hospedagem e transformando o hotel de lugar para descanso e pernoite, em um espaço para alimentação, relacionamento com outros hóspedes e/ou outros visitantes da própria cidade, assim como um possuidor de áreas e serviços para negócios e eventos, conforme observado nos Quadros 3 e 4.

\begin{tabular}{|c|c|c|c|c|c|c|c|c|c|}
\hline ÁREA SOCIAL & 1966 & 1972 & 1978 & 1984 & 1990 & 1996 & 2002 & 2008 & 2014 \\
\hline Restaurante & 3 & 6 & 16 & 23 & 37 & 43 & 58 & 58 & 57 \\
\hline Bar & 6 & 12 & 25 & 32 & 41 & 36 & 44 & 52 & s/i \\
\hline Garagem e estacionamento & 0 & 8 & 8 & 35 & 47 & 36 & 53 & 71 & 69 \\
\hline Sala de convenções & 0 & 0 & 0 & 24 & 35 & 36 & 53 & 56 & 55 \\
\hline Sauna & 0 & 0 & 0 & 3 & 7 & 14 & 4 & 35 & s/i \\
\hline Business center & 0 & 0 & 0 & 0 & 0 & 0 & 29 & 43 & s/i \\
\hline Sala de imprensa & 0 & 0 & 0 & 0 & 1 & 0 & 0 & 0 & s/i \\
\hline Ofurô & 0 & 0 & 0 & 0 & 0 & 0 & 0 & 3 & s/i \\
\hline Total de hotéis no período & 7 & 16 & 38 & 44 & 54 & 52 & 62 & 71 & 70 \\
\hline
\end{tabular}

Quadro 3: Número de hotéis por área social, período de 1966 a 2014

Fonte: Adaptado de Castro Ramos (2010).

No Quadro 3, destaca-se o aparecimento de salas de convenções a partir de 1984, mantendo-se presente em todos os anos sequenciais analisados na maioria dos hotéis listados nos guias, e do business center a partir do ano de 2002 apesar de em menor número, demonstrando que o turismo de negócios passa a ser também um segmento buscando pelos hotéis da cidade de Curitiba, reflexo da visibilidade em negócios que a cidade ganha com a criação da Cidade Industrial, e da chegada das montadoras e das multinacionais à cidade e região. Nota-se também a oferta de sauna em hotéis curitibanos onde, apesar da falta de informações em 2014, apresentou número expressivo em 2008.

Apesar da falta de informações em alguns itens registrados no ano de 2014, observa-se a presença de estabelecimentos de alimentos e bebidas dentro 
dos hotéis, transformando-se em opção de gastronomia para seus hóspedes, possibilitando que estes tenham experiências diferenciadas dentro dos hotéis, assim como opções de garagem e estacionamento, para caso o hóspede viaje de carro ou caso alugue um automóvel no local de destino.

\begin{tabular}{|c|c|c|c|c|c|c|c|c|c|}
\hline ÁREA DE LAZER & 1966 & 1972 & 1978 & 1984 & 1990 & 1996 & 2002 & 2008 & 2014 \\
\hline Piscina & 0 & 0 & 2 & 5 & 10 & 16 & 25 & 27 & 30 \\
\hline Sala de jogos & 0 & 0 & 0 & 6 & 2 & 1 & 0 & 0 & $\mathrm{~s} / \mathrm{i}$ \\
\hline Ginástica & 0 & 1 & 1 & 0 & 0 & 4 & 29 & 43 & 44 \\
\hline Quadra de futebol & 0 & 0 & 0 & 2 & 2 & 1 & 1 & 1 & $\mathrm{~s} / \mathrm{i}$ \\
\hline Playground & 0 & 0 & 0 & 3 & 4 & 1 & 1 & 1 & 1 \\
\hline Tênis/Squash/Paddle & 0 & 0 & 0 & 2 & 1 & 1 & 0 & 1 & 1 \\
\hline Quadra poliesportiva & 0 & 0 & 0 & 2 & 2 & 0 & 1 & 1 & $\mathrm{~s} / \mathrm{i}$ \\
\hline Cavalos & 0 & 0 & 0 & 1 & 1 & 0 & 0 & 0 & 0 \\
\hline Boate & 0 & 0 & 0 & 1 & 1 & 0 & 0 & 0 & 0 \\
\hline Minigolfe & 0 & 0 & 0 & 1 & 1 & 0 & 0 & 0 & 0 \\
\hline Churrasqueira & 0 & 0 & 0 & 0 & 3 & 0 & 0 & 0 & 0 \\
\hline Total de hotéis no período & 7 & 16 & 38 & 44 & 54 & 52 & 62 & 71 & 70 \\
\hline
\end{tabular}

Quadro 4: Número de hotéis por área de lazer, período de 1966 a 2014

Fonte: Adaptado de Castro Ramos (2010).

Outro aspecto que vale o destaque, apresentado no Quadro 4, apesar da falta de atualizações no ano de 2014, são as áreas de lazer, nas quais se observa a evolução e o aumento de sua presença, como piscinas e salas de ginástica nos hotéis curitibanos.

Dessa forma, por meio dos quadros e figura apresentados anteriormente, observam-se as ações e as estratégias de oferecimento de conforto e bemestar ao hóspede durante sua permanência nos hotéis, com o oferecimento de espaços extras de vivência, além de serviços diferenciados e tecnologias em unidades habitacionais, ressaltando-se que a coletividade das inovações praticadas pela hotelaria curitibana reflete também na competitividade da cidade como destinação turística que, conforme apontado pelo índice de competitividade dos 65 destinos indutores de 2014, posiciona Curitiba na liderança em muitos aspectos e, por fim, na quarta posição do índice geral (Brasil, 2014).

O processo de evolução da tecnologia e da inovação observado nos hotéis curitibanos avaliados pelo Guia Quatro Rodas no período selecionado, ante os eventos e os contextos históricos transcorridos, reforça o fenômeno de Path 
Plasticity que, conforme Strambach e Halkier (2013), caracteriza-se pela ação de stakeholders ante os eventos e os fenômenos dinâmicos transcorridos no espaço, por meio da inovação e da tecnologia, abrindo-se caminhos para nova exploração, sem contudo mudar o caminho natural desse fenômeno, porém se criando novas regras para que esse fenômeno gere desenvolvimento econômico e regional por meio da atividade turística.

Portanto, a atividade turística de negócios e lazer, alavancada pela chegada de empresas multinacionais, a instalação da Cidade Industrial de Curitiba, bem como os eventos esportivos da Copa do Mundo FIFA de 2014, geraram oportunidades dinâmicas à evolução econômica curitibana, conforme observado ao longo do tempo, reforçando processos de aprendizagem localizada por meio de mecanismos de desenvolvimento de conhecimento através da interação entre stakeholders, assim como destacado por Strambach (2008, como citado em Domareski Ruiz, 2015)

As observações realizadas por meio do estudo de dados da hotelaria curitibana validam a teoria de dependência da trajetória, ou path dependence, que ressalta o conhecimento gerado por contextos ou momentos históricos para o desenvolvimento econômico regional por meio de ações de stakeholders, resultando em inovações e processos assertivos de tomada de decisão (Bernardi, 2012).

\section{CONSIDERAÇÕES FINAIS}

Por meio da teoria de geografia econômica evolutiva, compreendeu-se a dinâmica evolutiva da hotelaria curitibana, bem como influências de stakeholders, observando-se sobretudo a busca por inovações e novos conhecimentos no que diz respeito às estratégias de gestão hoteleira para sua sobrevivência no mercado, tornando-se um ciclo competitivo entre concorrentes, em que um deve se destacar ou diferenciar-se dos demais, seja em preço, seja em equipamentos, seja em funcionalidades, seja em design, seja em inovação, entre outros.

Destaca-se neste processo evolutivo a preocupação dos hotéis em oferecer cada vez mais atividades ao hóspede dentro de sua propriedade, como restaurantes, bares, atividades de lazer e desportivas, academia, entre outros, 
além de equipamentos em seus quartos, os quais alguns foram considerados quase que obrigatórios devido à quantidade destes equipamentos nos hotéis da cidade, tais como acesso à internet e ao wi-fi, canais de televisão a cabo e ar-condicionado, ao passo em que outras preocupações de alguns hóspedes nem sempre são contemplados por hotéis, tal como os quartos adaptados para deficientes físicos e/ou idosos, além de localização favorável para o deslocamento de seus hóspedes próximos aos pontos de acesso à cidade (Rodoferroviária e Aeroporto Afonso Pena), e pontos de interesse corporativo e lazer (área central e intermediações).

Portanto, como resposta à problemática de estudo (Existe relação entre a evolução socioeconômica de Curitiba e a dinâmica evolutiva da hotelaria curitibana no período de 1966 a 2014?), nota-se que a dinâmica evolutiva da hotelaria curitibana possuiu momentos de alavancagem em número de hotéis durante os períodos históricos (1) Criação da Cidade Industrial de Curitiba e; (2) Chegada das montadoras de automóveis e multinacionais à cidade de Curitiba e região metropolitana. No entanto, este incremento em números não foi observado durante a Copa do Mundo FIFA 2014, dado que a hotelaria da capital paranaense foi considerada suficiente para a demanda deste evento, permitindo que a mesma não sofresse com problemas de 'superoferta' na hoteleira após o evento esportivo no Brasil. Observou-se, também, que a instalação de novos hotéis na cidade acompanhou sobretudo a dinâmica evolutiva da própria economia brasileira, ao passo em que a atividade turística ganha mais visibilidade por conta da democratização das viagens e das próprias viagens de negócios, em especial após o período de instabilidade econômica e de hiperinflação vivenciadas nos anos de 1980 e início dos anos 1990.

Dessa forma, observou-se durante a análise de dados obtidos que a evolução hoteleira na cidade de Curitiba é um processo contínuo, pautada em inovação e na busca por novos espaços no mercado, aproveitando-se contextos e momentos econômicos, cuja intenção é a obtenção de conhecimento em gestão e tomada de decisão, fornecendo subsídios para momentos futuros em decorrência de sua dependência de trajetória, como forma de proteção à sua própria sobrevivência e continuidade no mercado, sendo este também uma forma de diferenciação competitiva. 
Os resultados e as observações obtidos por meio deste estudo não encerram o tema de dinâmica hoteleira sob a luz da teoria de geografia econômica evolutiva, mas sim abrem caminhos para novas pesquisas, sugerindo-se a observação desse fenômeno em outras capitais e/ou cidades do Brasil, de modo a observar se os processos históricos transcorridos nesses municípios alavancam ou contribuem para o processo evolutivo, inovador e competitivo da hotelaria destes locais.

\section{REFERÊNCIAS BIBLIOGRÁFICAS}

Arthur, W.B. (1994) Increasing returns and path dependence in the economy. Ann Arbor: University of Michigan Press.

Aldrich, H. et al. (2008) In defence of Generalised Darwinism. Journal of Evolutionary Economics. New York, v. 18, n. 5, p. 577-596.

Bernardi, B.B. (2012) O conceito de dependência da trajetória (path dependence): Definições e controvérsias teóricas. Perspectivas, São Paulo, v.14, p.137-167.

Boschma, R. \& Martin, R. (2010) The handbook of evolutionary economic geography. Cheltenham: Edward Elgar.

Brasil. Ministério do Turismo. (2014) Índice de competitividade do turismo nacional, Brasília: Ministério do Turismo. Disponível em: <http://www.turismo.gov.br/sites/ default/turismo/o_ ministerio/publicacoes/downloads_publicacoes/indice_Brasil_2014_2.pdf> Acesso em 20 de maio de 2016.

Brouder, P. \& Eriksson, R. (2013) Tourism evolution: On the synergies of tourism studies and evolutionary economic geography. Annals of tourism research, n.43, p.370-389.

Byrne, D. (1998) Complexity theory and the social sciences: An introduction. London and New York: Routledge.

Castro Ramos, S.E.V.d. (2010) A dinâmica da localização da hotelaria curitibana no período de 1966 a 2008. Tese (doutorado). Universidade Federal do Paraná, Curitiba: Universidade Federal do Paraná

Carlos, A. F. A. Da (2016) "organização" à "produção" do espaço no movimento do pensamento geográfico. In: CARLOS, A. F. A.; SOUZA, M. L.; BELTRÃO SPOSITO, M. E. (org). A produção do espaço urbano: Agentes e processos, escalas e desafios. São Paulo: Contexto. p. 53-74 
Chorincas, J. (2009) Geografia econômica: Encontros e desencontros de uma ciência de encruzilhada, Inforgeo, Lisboa: Edições Colibri. p.109-122.

Coriolano, L.N.T.M. et. al. (2009) Arranjos produtivos locais do turismo comunitário: Atores e cenários em mudança. Fortaleza: EdUECE.

Curitiba, Região e Litoral Convention \& Visitors Bureau. (s/d) Curta Curitiba mais 2 dias. Disponível em: <http://www.curitibacvb.com.br/page/curta-curitiba-mais-2-dias> Acesso em 10 de Maio de 2017

Curitiba Turismo. (s/d) História. Curitiba: Prefeitura de Curitiba. Disponível em: < http://www. turismo.curitiba.pr.gov.br/conteudo/historia/6> Acesso em: 20 de maio de 2016.

Egan, D.J. \& Nield, K. (2000) Towards a theory of intraurban hotel location. Urban studies, vol.37, n³, p.611-621

Fernandes, A.S.A. (2002) Path depedency e os estudos históricos comparados. BIB, São Paulo, n. 53, p. $79-102$

Fórum de Operadoras Hoteleiras do Brasil (FOHB); HOTEL INVEST. (2015) Placar hotelaria. Disponível em: < http://www.abeoc.org.br/wp-content/uploads/2014/03/ Placar-daHotelaria-2015.pdf> Acesso em 07 de junho de 2016.

França, J.P. (2016) Lazer, turismo e espaço urbano: A reconversão portuária na cidade de Santa Fé, Argentina. Revista Turismo em Análise, v.27, n². São Paulo: Universidade de São Paulo.

Frenken, K (Ed). (2007) Applied evolutionary economics and economics geography. Edward Elgar: Cheltenham.

Hayllar, B. \& Edwards, D.; Griffin, T.; Aldrigui, M. (2011) Turismo em cidades: Espaços urbanos, lugares turísticos. Rio de Janeiro: Elsevier.

Hocayen-da-Silva, A.J. \& Teixeira, R.M. (2007) Ambiente competitivo e vantagem competitiva a partir de uma abordagem integradora: Estudo de caso no setor hoteleiro em Curitiba. Turismo - Visão e ação, v.9, n¹, p.19-35.

IBGE - Instituto Brasileiro de Geografia e Estatística (2016). Cidades: Paraná > > Curitiba. IBGE, Disponível em: < http://cidades.ibge.gov.br/xtras/perfil.php?Lang=\& codmun=4106902> Acesso em 20 de Maio de 2016.

Ioannides, D., Halkier, H. \& Lew, A.A. (2015) Evolutionary Economic Geography and the Economies of Tourism Destinations. Disponível em: <http://www.tgjournal.com/ tourism-place-blog/evolutionary-economic-geography-and-the-economies-of-tourismdestinations> Acesso em 25 de maio de 2016. 
Garud, R. \& Karnoe, P. (2001) Path Creation as a process of mindfull deviation. In: GARUD, R. \& KARNOE, P. (Eds.) Path dependence and creation. Mahwah: Lawrence Earlbaum Associates.

Laville, C. \& Dione, J. (1999) A construção do saber: Manual de metodologia da pesquisa em ciências humanas. Porto Alegre: Artmed; Belo Horizonte: Editora UFMG.

Limonad, E. (1999) Reflexões sobre o espaço, o urbano e a urbanização. GEOgraphia, Rio de Janeiro, Ano 1, n¹, pp.71-91, 1999.

Nunes, M.R.O. (2014) Turismo e a produção do espaço em João Pessoa - PB. Revista Turismo - Visão e Ação - Eletrônica, v.16, n² 2. Balneário Camboriú: Universidade do Vale do Itajaí - UNIVALI.

Oliveira, B. \& Gândara, J.M.G. (2015) Satisfação e fidelidade a um destino da Copa do Mundo FIFA 2014. Revista Turismo em Análise, v.26, n¹, especial. São Paulo: Universidade de São Paulo.

Paiva, R.A. (2008) O turismo, a produção e o consumo do espaço. In: Anais do II Colóquio Internacional sobre o comércio e a cidade: Relações de origem. São Paulo. Disponível em: < http://www.labcom.fau.usp.br/wp-content/uploads/2015/05/2cincci/ 6005\%20Paiva. pdf $>>$ Acesso em 15/11/2016.

Pearce, D.G. (2003) Geografia do turismo: Fluxos e regiões no mercado de viagens. São Paulo: Aleph.

Peixoto, F. (Ed.) (2013) Guia Quatro Rodas: Brasil 2014. São Paulo: Editora Abril.

Pereira, P.C.X. \& Spolon, A.P.G. (2007) Turismo, hotelaria e imagem urbana: A construção e o consumo de espaços de simulação. Revista eletrônica de geografia y ciencias sociales, vol XI, no 245 (59). Barcelona: Universidad de Barcelona.

Porter, M.E. (1999) Competição: Estratégias competitivas essenciais. Rio de Janeiro: Elsevier.

Domareski Ruiz, T.C., Miki, A.F.C. \& Gândara, J.M. (2014) A geografia econômica evolutiva como perspectiva de análise da dinâmica dos destinos turísticos. Caderno Virtual de Turismo, Rio de Janeiro, v.14, n.3, p.316-336.

Domareski Ruiz, T.C. (2015) A dinâmica evolutiva da competitividade do destino turístico Curitiba. Tese (doutorado). Universidade Federal do Paraná, Curitiba: Universidade Federal do Paraná.

Santos, M. (1982) Pensando o espaço do homem. São Paulo: Hucitec.

Schmid, C. (2012) A teoria da produção do espaço de Henri Lefebvre: Em direção a uma dialética tridimensional. GEOUSP - Espaço e tempo, São Paulo, n³2, pp.89-109. 
Shoval, N., Mckercher, B., Ng, E. \& Birenboim, A. (2011) Hotel location and tourist activity in cities. Annals of tourism research, v.38, n4, p. 1594-1612.

Tôrres, J.J.M. (2015) Teoria da complexidade: Uma nova visão de mundo para a estratégia. Anais do I Encontro Brasileiro de Estudos da Complexidade - I EBEC. Curitiba, Paraná, Brasil.

Trotta, S.F., Strehlau, V.I. \& Turolla, F.A. (2014) As mudanças na imagem das cidades de Curitiba e Florianópolis: Um estudo sobre os reflexos da divulgação das cidades sedes para a Copa do Mundo da FIFA de 2014.

\section{CONTRIBUIÇÃO DOS AUTORES NA CONSTRUÇÃO DO ARTIGO}

GUIZI: Pesquisa e escrita

GÂNDARA: Pesquisa e orientação 